Research Article

Oopen Access

D) CrossMark

\title{
Voice disorders among academic staff at king saud university medical college (comparison between basic science and clinical staff)
}

\begin{abstract}
Background: Voice disorders are a common problem among general population, Medical academic staff are like teachers at high risk for developing voice disorders. Some diseases and personal behaviors can be risk factors for voice disorders like smoking, caffeine drink and Laryngopharyngeal reflux.
\end{abstract}

Objectives: To know the prevalence of voice disorders and reflux symptoms among Academic Staff at King Saud University (Medical college), to compare it between Basic Science and Clinical staff and to know the risk factors.

Design: Cross sectional study.

Setting: Study done at King Saud University (College of Medical) during one year period.

Interventions: Questionnaires

Patients (Participants): Basic science and clinical academic staff at King Saud University (College of Medical) Main outcome measures: Habits that could affect the voice, variable of teaching characteristics, Voice Handicap Index and Reflux Symptom index.

Results: Total numbers were 103 participants. Most of the participants were Saudis; males are more than female. The percentage of participants with positive VHI and RSI are 38.8 $\%, 57.3 \%$, respectively. There is a significant relation between abnormal voice handicap score and loud voice. Also, the relation is significant with abnormal voice handicap score and abnormal reflux symptoms index score.

Conclusion: Voice disorders are well known problems among teaching staff. It is common among Saudi academic staff and among academic staff with abnormal reflux symptoms index and using loud voice. There is no statistically significant difference in voice handicap index score between basic and clinical academic staff.

Limitations: It is a cross sectional study, the result will be more accurate if the study was randomized control trial with objective measure rather than subjective which can be done in further research. There is no previous study done for university acadmic staff to compare our result with it .

Keywords: saudi arabia, dysphonia, laryngopharyngeal reflux, voice handicap index, voice disorders
Volume 8 Issue I - 2017

\author{
Elaf E Ahmed,' Manal A Bukhari, ${ }^{2}$ Reem A \\ Melibary ${ }^{3}$ \\ Otolaryngology resident at Prince Sultan Military Medical City, \\ Saudi Arabia \\ ${ }^{2}$ Otolaryngology Consultant at King Abdul Aziz University \\ Hospital King Saud University, Saudi Arabia \\ ${ }^{3}$ Medical resident at Security Forces Hospital, Saudi Arabia
}

Correspondence: Elaf Ahmed Otolaryngology resident at Prince Sultan Military Medical City Prince Sultan Military Medical City Riyadh, Saudi Arabia, Tel 966 I 4775735, Email dr.elafl989@gmail.com

Received: May 28, 2017 | Published: July 14, 2017
Abbreviations: VHI, voice handicap index; RSI, reflux symptom index; LPR, laryngopharyngeal reflux

\section{Introduction}

Voice disorders are a common occupational problem especially among voice user population like: teachers, singers and interviewers because their voice is the primary tool for their occupation and they use it frequently in high volume. ${ }^{1-2}$ Voice disorders may affect their quality of life, functions and performance in work leading to frequent absence from work. One study showed that one fifth of the teachers had a history of absence from work due to voice problems. ${ }^{3-4}$ Staff with voice problems frequently seeks medical help and their voice improved during holidays. ${ }^{5}$ Voice disorders may lead to high cost effect on the patients and health organizations. ${ }^{5}$ The prevalence of voice disorders among professional voice users is more common than in the general population. ${ }^{1}$

Voice handicap index questionnaire is a tool to measure voice disorders. It is introduced by Jacobson in 1997 to quantify the functional, physical and emotional impacts of voice disorder on a patient's life. It consists of 30 questions about the severity of the voice problem. ${ }^{6-8}$ There is a modified version of voice handicap index which contain 10 questions (VHI-10). ${ }^{9}$ Laryngopharyngeal reflux (LPR) is one of the important risk factor for voice problems. Most of the patient with LPR is complaining of hoarseness, throat clearing, dysphonia, chronic cough and foreign body sensation in throat. Presence of LPR can be detected by Reflux symptom index questionnaire which contain 9 questions about past month symptoms of reflux. ${ }^{10}$ Smoking, caffeine intake, voice abuse, noisy background, history of trauma or surgery and female gender are all considered risk factors for voice disorders ${ }^{5.11}$ Although a trial of proton pump inhibitors has been suggested to be cost-effective for treatment and diagnosis of LPR Health education and prevention by life style modification are the best tools to overcome this problem. ${ }^{12}$

The goals of this study are to compare the prevalence of voice disorders and reflux symptoms among two groups of medical staff, basic science and clinical academic staff at King Saud University (Medical College) and to know the risk factors for voice disorders. 


\section{Materials and methods}

This is a cross sectional study of two groups of basic science and clinical academic staff at King Saud University (Medical College), Riyadh, Saudi Arabia; done during one year period. Questionnaires were distributed during a one month period among the academic staff. The questionnaire takes less than 10 minutes to be completed. It includes: demographic data, habits that could affect the voice (loud voice-smoking-caffeine and water drink). Variable of teaching characteristics (years of experience-grade of teaching (basic or clinical subjects)-numbers of teaching session per week, voice activity outside the work). Voice Handicap Index (VHI) and Reflux symptom index (RSI), VHI-10 questionnaire was used. Maximum score is 40; more than 11 indicate abnormal scores. ${ }^{8,9}$ For LPR disease, reflux symptom index questionnaire was used; more than 13 scores indicate presence of reflux. ${ }^{10}$

Statistical analysis done by SPSS version 20. The study has been approved by local institutional review board committee with number E-15-1395.

\section{Results and discussion}

The total number of participants was 103 academic staff. Most of the participants were Saudis $56(54.4 \%)$. Male to female ratio was $2: 1$. Fifty-five participants $(53.4 \%)$ were basic science academic staff and $48(46.6 \%)$ were clinical academic staff. Among academic staff in general $40(38.8 \%)$ had abnormal VHI while 59(57.3 \%) had abnormal RSI. The statistically significant relation considered when $\mathrm{p}-$ value $<0.05$. VHI score is significantly abnormal among Saudi academic staff (Table 1). Loud voice is significantly related to abnormal VHI (Table 2). No significant relation between VHI score and academic staff teaching characteristics like teaching grade schools was found (Table 3). There is a statistically significant relation between abnormal VHI score and abnormal RSI, $\mathrm{p}$ value $=0.002$. Patients with abnormal VHI are more predisposing to have abnormal reflux symptoms (Table 4). No significant difference in prevalence of abnormal VHI scores and abnormal RSI scores between basic science and clinical academic staff (Table $5 \& 6$ ).

Table I Voice handicap index result based on demographic data of the academic staff

\begin{tabular}{|c|c|c|c|c|}
\hline \multicolumn{2}{|c|}{ Demographic Data } & \multirow{2}{*}{$\begin{array}{l}\mathbf{N} \\
70 \\
\end{array}$} & \multirow{2}{*}{$\begin{array}{l}\text { P-Value } \\
0.26 \\
\end{array}$} & \multirow{2}{*}{$\begin{array}{l}\text { Significance } \\
\text { NS }\end{array}$} \\
\hline Gender & Male & & & \\
\hline & Female & 33 & & \\
\hline \multirow{2}{*}{ Age } & $30-39$ & 29 & 0.78 & NS \\
\hline & 40 & 74 & & \\
\hline \multirow[t]{2}{*}{ Nationality } & Saudi & 56 & 0.001 & Significant \\
\hline & Non-Saudi & 47 & & \\
\hline
\end{tabular}

Table 2 Voice handicap index scores based on academic staff habits

\begin{tabular}{|c|c|c|c|c|}
\hline \multicolumn{2}{|c|}{ Academic Staff Habits } & \multirow{2}{*}{$\begin{array}{l}\mathbf{N} \\
58\end{array}$} & \multirow{2}{*}{$\begin{array}{l}\text { p-value } \\
45\end{array}$} & \multirow{2}{*}{$\begin{array}{l}\text { Significance } \\
\text { Significant }\end{array}$} \\
\hline Loud Voice & Yes & & & \\
\hline & No & 45 & & \\
\hline \multirow[t]{2}{*}{ Smoking } & Yes & 13 & 0.705 & NS \\
\hline & No & 90 & & \\
\hline \multirow[t]{2}{*}{ Passive Smoking } & Yes & 36 & 0.164 & NS \\
\hline & No & 67 & & \\
\hline \multirow[t]{4}{*}{ Coffee } & None & 6 & 0.79 & NS \\
\hline & 1 & 13 & & \\
\hline & 3-Feb & 38 & & \\
\hline & $>3$ & 46 & & \\
\hline
\end{tabular}

Table Continued...

\begin{tabular}{|c|c|c|c|c|}
\hline \multicolumn{2}{|c|}{ Academic Staff Habits } & \multirow{2}{*}{$\frac{\mathbf{N}}{103}$} & \multirow[t]{2}{*}{ p-value } & \multirow[t]{2}{*}{ Significance } \\
\hline & Total & & & \\
\hline \multirow[t]{7}{*}{ Water } & 0.25 & 4 & 787 & NS \\
\hline & 0.5 & 16 & & \\
\hline & I & 32 & & \\
\hline & 1.5 & 29 & & \\
\hline & 2 & 15 & & \\
\hline & $>2$ & 7 & & \\
\hline & Total & 103 & & \\
\hline \multirow[t]{4}{*}{$\begin{array}{l}\text { Session Beside } \\
\text { Work }\end{array}$} & $<=5$ & 31 & 779 & NS \\
\hline & 6-Oct & 42 & & \\
\hline & $>10$ & 30 & & \\
\hline & Total & 103 & & \\
\hline
\end{tabular}

Table 3 Voice handicap index scores of the teacher based on variable of teaching characteristics

\begin{tabular}{lllll}
$\begin{array}{llll}\text { Teaching } \\
\text { Characteristics }\end{array}$ & N & p-value & Significance & \\
\hline Experience & $<=5$ & 18 & 0.908 & NS \\
& $10-$ Jun & 23 & & \\
& I5-Nov & 21 & & \\
& $16-20$ & 18 & & \\
& $>20$ & 23 & & NS \\
Total & 103 & & NS \\
Grade & Basic & 55 & 0.221 & \\
& Clinical & 48 & & \\
& $<=10$ & 15 & 0.161 & \\
& $15-N o v$ & 22 & & \\
& $16-20$ & 27 & & \\
& $21-30$ & 29 & & \\
& $>30$ & 10 & & \\
& Total & 103 & & \\
&
\end{tabular}

Table 4 Voice handicap index scores of the teacher based on variable of reflux symptoms index

\begin{tabular}{lllll}
\hline Reflux & Symptoms Index & N & p-value & Significance \\
\hline RSI & Normal & 56 & 0.002 & Significant \\
\hline \multicolumn{2}{c}{ Abnormal } & 47 & &
\end{tabular}

Table $\mathbf{5}$ Voice handicap index in relations with teaching grades

\begin{tabular}{llll}
\hline Grades & Basic N/\% & Clinical N/\% & Total N/\% \\
\hline VHI & & & \\
Normal & $39 / 60.9$ & $25 / 39$ & $64 / 100$ \\
Abnormal & $16 / 4 I$ & $23 / 58.9$ & $39 / 100$ \\
Total & $55 / 53.4$ & $48 / 46.6$ & $103 / 100$ \\
RSI & & & \\
Normal & $30 / 53.6$ & $26 / 46.4$ & $56 / 100$ \\
Abnormal & $25 / 53.2$ & $22 / 46.8$ & $47 / 100$ \\
Total & $55 / 53.4$ & $48 / 46.6$ & $103 / 100$ \\
\hline
\end{tabular}

Abbreviations: VHI, voice handicap index; RSI, reflux symptom index; NS, non significant; $\mathrm{N}$, numbers

Voice disorders are common among teachers and any professional voice users such as academic staff. Teachers and academic staff are at higher risk than general population to develop voice disorder. ${ }^{4}$

A study done in Poland reported that the overall lifetime vocal symptoms such as chronic hoarseness, aphonia and dryness in the throat were more frequent in the primary and secondary teachers than in non-teachers, $69 \%, 36 \%$, respectively. ${ }^{13}$ 
In another study done among the same population, more than half of the teachers reported voice problem during their career. ${ }^{4}$

While in Thomas G, et al. research $39.6 \%$ of the student teachers and $32.6 \%$ of the general population reported voice complaints at the moment of study and/or over the past year. ${ }^{1}$ In Spanish teachers 57\% of the teachers have voice disorders and $45 \%$ in Kristen, et al. study reported vocal difficulties. ${ }^{10-14}$

This is the first study addressing voice disorders among university academic staff which was $38.8 \%$ this finding is lower than in school teachers. ${ }^{1-4,13,14}$

Voice complaints are more in lower grades school teachers than in university academic staff. This maybe because of the need to use loud voice especially in noisy background as in low grades school. We found that using of loud voice has significant relation with abnormal VHI score $\mathrm{p}$-value $=0.045$

Several studies consider stress as one of the risk factor for voice problem mainly due to student's attitude especially in school teachers. ${ }^{1-5}$ We found no gender difference in prevalence of voice disorder, but other studies report that female are more prone to have voice disorders and organic lesion. ${ }^{2-4,14}$ Age has no significant impact on voice problem in our study as well as in a study done among Dutch teachers. ${ }^{4}$ Also, years of experience has no impact on voice problem. ${ }^{2}$ Smoking, drinking coffee and tea were found to be risk factors for voice problem in a study done in Spain but no significant correlation has been found in our study. ${ }^{14} \mathrm{LPR}$ is considered one of the risk factors for abnormal VHI in our study.

\section{Conclusion}

Voice disorders are more common among Saudi academic staff. Thirty-eight percent of staff had abnormal VHI and $57 \%$ had abnormal RSI. There is significant correlation between abnormal VHI with abnormal RSI and using loud voice. No statistically significant relation between abnormal VHI scores and academic staff teaching grades.

\section{Acknowledgments}

None.

\section{Conflicts of interest}

Author declares there are no conflicts of interest.

\section{Funding}

None.

\section{References}

1. Thomas G, de Jong FI, Cremers CW, et al. Prevalence of Voice Complaints, Risk Factors and Impact of Voice Problems in Female Student Teachers. Folia Phoniatr Logop. 2006;58(2):65-84.

2. Thibeault SL, Merrill RM, Roy N, et al. Occupational Risk Factors Associated with Voice Disorders among Teachers. Ann Epidemiol. 2004;14(10):786-792.

3. Pizolato RA, Rehder MI, Meneghim Mde C, et al. Impact on quality of life in teachers after educational actions for prevention of voice disorders: a longitudinal study. Health Qual Life Outcomes. 2013;11:28.

4. de Jong FI, Kooijman PG, Thomas G, et al. Epidemiology of Voice Problems in Dutch Teachers. Folia Phonia Logop. 2006;58(3):186-198.

5. Simberg S. Prevalence of Vocal Symptoms and Voice Disorders Among Teacher Students and Teachers and a Model of Early Intervention. University of Helsinki, Faculty of Behavioural Sciences, Department of Speech Sciences, Finland. 2004.

6. Rosen CA, Lee AS, Osborne J, et al. Development and validation of the voice handicap index-10. Laryngoscope. 2004;14(9):1549-1556.

7. Moy FM, Hoe VCW, Hairi NN, et al. Determinants and Effects of Voice Disorders among Secondary School Teachers in Peninsular Malaysia Using a Validated Malay Version of VHI-10. PLoS One. 2015;10(11):e0141963.

8. Jacobson B, Johnson A, Grywalski C, et al. Voice Handicap Index (VHI): development and validation. Am J Speech Lang Pathol. 1997;6:66-70.

9. Arffa RE, Krishna P, Gartner-Schmidt J, et al. Normative Values for the Voice Handicap Index-10. J Voice. 2011;26(4):462-465.

10. Belafsky P, Postma G, Koufman J. Validity and reliability of the reflux symptom index (RSI). J Voice. 2002;16(2):274-277.

11. Higgins K, Smith A. Prevalence and Characteristics of Voice Disorders in a Sample of University Teaching Faculty. Contemporary Issues in Communication Science and Disorders. Fall. 2012;39:69-75.

12. Campagnolo AM, Priston J, Thoen RH, et al. Laryngopharyngeal Reflux: Diagnosis, Treatment, and Latest Research. Int Arch Otorhinolaryngol . 2014;18:184-191.

13. Sliwinska-Kowalska M, Niebudek-Bogusz E, Fiszer M, et al. The Prevalence and Risk Factors for Occupational Voice Disorders in Teachers. Folia Phoniatr Logop. 2006;58(2):85-101.

14. Preciado-López J, Pérez-Fernández C, Calzada-Uriondo M, et al. Epidemiological Study of Voice Disorders Among Teaching Professionals of La Rioja. J Voice. 2010;22(4):489-508. 